\title{
Prácticas Preventivas dentro de la Ventana de Infectividad dental por parte de madres lactantes, pacientes del Hospital Universitario Angel Larralde, en Carabobo, Venezuela.
}

\section{Resumen}

Objetivo: El objetivo de investigación es identificar mediante la educación para la salud el nivel de conocimiento de las madres de las madres referente a la ventana de infectividad bucal en el binomio madre-hijo y a las prácticas preventivas. Materiales y Métodos: La muestra fue tomada durante la consulta de obstetricia del Hospital Universitario Ángel Larralde, estado Carabobo en el período Septiembre-Diciembre del año 2017. Previamente, las madres habían recibido instrucción referente a técnicas de higiene personal y bucal por parte de los residentes del Postgrado de Odontopediatría de la Universidad de Carabobo. El enfoque de la investigación es cualitativo, modalidad de campo de tipo descriptiva, diseño no experimental transversal. La muestra fue de treinta (30) madres. Los datos se
Patricia Catarí, ${ }^{1}$ Gloriana Portocarrero, ${ }^{2}$ Federico Ojeda, ${ }^{3}$ Ingrid Hoffmann. ${ }^{4}$ recolectaron por medio de la técnica de la encuesta usando como un cuestionario contentivo de veinticinco (25) preguntas, sobre las dimensiones contacto directo, lactancia materna e higiene personal. Los datos obtenidos fueron organizados y presentados en tablas. Resultados: Se obtuvo un nivel de conocimiento de la transmisibilidad bacteriana por contacto directo regular. El nivel de conocimiento de las prácticas preventivas durante la lactancia materna fue deficiente, a diferencia del conocimiento referente a las medidas de higiene personal que fue aceptable. Conclusión: Se concluyó que los indicadores contacto directo y lactancia materna deben ser reforzadas.

Palabras clave: Prevención, Ventana de Infectividad, Transmisibilidad, Caries Dental, Madres, Lactantes. 


\section{Práticas Preventivas dentro da Janela da Infectividade Dentária por parte das mães lactentes, pacientes do Hospital Universitário Angel Larralde, em Carabobo, Venezuela.}

\section{Resumo}

Objetivo: O objetivo da pesquisa é identificar, por meio da educação em saúde, o nível de conhecimento das mães em relação à janela de infectividade bucal no binômio mãe-filho e práticas preventivas. Materiais e Métodos: A amostra foi retirada durante a consulta de obstetrícia do Hospital Universitário Ángel Larralde, no estado de Carabobo, no período de setembro a dezembro de 2017. Anteriormente, as mães recebiam instruções sobre técnicas de higiene pessoal e bucal por parte das crianças. Residentes do Curso de Pós-Graduação em Odontopediatria da Universidade de Carabobo. O foco da pesquisa foi qualitativo, modalidade de campo do tipo descritiva, delineamento transversal não experimental. A amostra foi de trinta (30) mães. Os dados foram coletados por meio da técnica de pesquisa, utilizando-se um questionário contendo vinte e cinco (25) questões, sobre as dimensões contato direto, amamentação e higiene pessoal. Os dados obtidos foram organizados e apresentados em tabelas. Um nível de conhecimento da transmissibilidade bacteriana foi obtido por contato direto regular. O nível de conhecimento das práticas preventivas durante a amamentação foi deficiente, diferentemente do conhecimento sobre medidas de higiene pessoal aceitável. Concluiu-se que os indicadores contato direto e amamentação devem ser reforçados.

Palavras chaves: Prevenção, Janela de Infectividade, Transmissibilidade, Cárie Dentária, Mães, Bebês.

Original article

\section{Preventive Practices within the Window of Dental Infectivity by breastfeeding mothers, patients of Angel Larralde University Hospital, in Carabobo, Venezuela.}

\section{Abstract}

Purpose: The objective of the research is to identify, through health education, the level of knowledge of mothers regarding the window of oral infectivity in the motherchild binomial and preventive practices. Materials and Methods: The sample was taken during the obstetrics consultation of the Ángel Larralde University Hospital, Carabobo state, in the period SeptemberDecember of the year 2017. Previously, the mothers had received instruction regarding techniques of personal and oral hygiene on the part of the children. Residents of the Postgraduate Course in Pediatric Dentistry 
of the University of Carabobo. The focus of the research is qualitative, field modality of descriptive type, transversal nonexperimental design. The sample was thirty (30) mothers. The data was collected by means of the survey technique using as a questionnaire containing twentyfive (25) questions, about the dimensions direct contact, breastfeeding and personal hygiene. The data obtained were organized and presented in tables. A level of knowledge of bacterial transmissibility

\section{Introducción}

La Odontología del siglo XXI ha asumido nuevos retos que incluyen un abordaje más integral al tradicional clínico quirúrgico, incluyendo un énfasis en abordajes tempranos para pacientes infantes y sus madres, prevención basada en niveles de riesgo, y manejo integral de la enfermedad. En relación a ello, es de dominio común en la profesión que caries dental es una enfermedad que tiene un componente infeccioso, donde participan en su transmisibilidad una serie de bacterias entre las cuales destaca, el Streptococcus mutans (S. mutans). ${ }^{1}$ Dicha transmisibilidad ocurre a través de la ventana de infectividad bucal en el binomio madre-hijo, es decir, por el pasaje de la flora microbiana durante los primeros días de vida, en forma directa, a través del pezón materno, durante la interacción de besos, utensilios del bebe y a través de las manos de quienes conforman el núcleo familiar, creándose de esta manera potenciales circuitos de infectividad. ${ }^{2}$

A la edad de 12 meses, los bebés comienzan a establecer un entorno oral que los coloca en riesgo de padecer caries dental. Se ha was obtained by regular direct contact. The level of knowledge of preventive practices during breastfeeding was deficient, unlike the knowledge regarding personal hygiene measures that was acceptable. It was concluded that the indicators direct contact and breastfeeding should be reinforced.

Key words: Prevention, Window of Infectivity, Transmissibility, Dental Caries, Mothers, Infants.

demostrado que la caries dental es una enfermedad infecciosa y transmisible. El S. mutans ha sido implicado como la principal bacteria responsable del inicio de la caries dental en niños durante la primera infancia, debido a que la colonización requiere la presencia de una superficie dura y no desplazable, los bebés no albergan estos organismos hasta algún tiempo después de que emergen los dientes. $^{2}$

Los bebés adquieren $S$. mutans principalmente de sus madres, la adquisición inicial de estas bacterias parece ocurrir durante un rango de edad bien delineado (ventana de infectividad), que se estima que es de 19 a 31 meses de edad. La adquisición más temprana de la bacteria ha sido asociada con ciertos factores de riesgo, como caries dental entre hermanos, caries dental maternas, hábitos alimenticios y prácticas de higiene oral deficientes. Por lo tanto, los bebés deben recibir una intervención clínica temprana antes de la ventana de infectividad establecida, y los padres deben recibir las recomendaciones sobre las prácticas de higiene oral y de alimentación adecuadas durante la infancia y los años preescolares. 
Una de estas medidas es la limitación de la frecuencia de ingesta de alimentos y líquidos que promueven la producción de ácidos. $^{3}$

Por consiguiente, se conoce que existen etapas en el ser humano en donde, se es más vulnerable para adquirir bacterias, las cuales podrían causar alteraciones en el equilibrio biológico y funcional de las personas. Estas etapas se conocen como "ventanas de infectividad". En el caso de la caries dental, corresponde al periodo durante el cual el ser humano es más susceptible a adquirir bacterias, en consecuencia, se incrementa el riesgo de la aparición precoz de la caries dental. ${ }^{3}$

La ventana de infectividad ha sido estudiada solo por algunos científicos como Caufiedl ${ }^{4}$ y Ramos $^{5}$ que han estudiado la dentición primaria y permanente, es en este período de tiempo en el que la adquisición inicial de $S$. mutans tiene lugar en un diente primario. Tanto los dientes primarios como los permanentes permanecen en la cavidad bucal durante un tiempo importante $\mathrm{y}$, por lo tanto, proporcionan una superficie de tejido completamente virgen para que los microorganismos puedan atacar. Esto permite que el $S$. mutans colonice en la cavidad bucal antes de que otras bacterias hagan la ventana de infectividad para dientes primarios se presenta desde los 7 y hasta 31 meses de vida. Esta ventana de infectividad es importante porque indica el período en el que las bacterias inician su actividad y por consiguiente la formación de caries dental. ${ }^{4,5}$

Uno de los factores que influye en este proceso infectocontagioso, es la falta de información acerca de las prácticas preventivas de la transmisibilidad bacteriana por parte de las gestantes. La transmisión materno infantil de bacterias orales es un mecanismo potencial de la infección oral en el desarrollo de la caries dental. La salud puede ser transmitida de padres a hijos, posiblemente perpetuando disparidades de salud y proporcionando razones para considerar los determinantes intergeneracionales en la prevención de enfermedades. Es por ello, que surge la necesidad de identificar actividades educativas dirigidas a las madres de forma oportuna y efectiva durante el periodo prenatal con la finalidad de brindarles la información requerida y necesaria en aras de concienciar sobre la infectividad bucal y los mecanismos o métodos para prevenir dicho proceso infectocontagioso. ${ }^{6}$

Es de hacer notar, que todo programa educativo requiere en primera instancia, el diagnóstico de la necesidad de la aplicación del mismo. En el caso de la transmisibilidad bacteriana en el binomio madre-hijo, antes de diseñar cualquier estrategia, se debe evaluar los conocimientos y la actitud con respecto a las prácticas preventivas de las gestantes del grupo a quienes se dirigió el programa en cuestión. ${ }^{7}$

En el año 2010 Castaño, H. et al ${ }^{8}$. aplicaron instrumentos educativos, evaluando el conocimiento con respecto a las técnicas de higiene bucal. Así mismo, en este estudio, se logró demostrar la importancia de la prevención de la caries dental, en el cual se logró comparar los cambios de actitud positivos en las madres luego de evaluar la falta de conocimientos y recibir oportunamente la información pertinente acerca de cómo prevenir y hacer buen uso de las medidas de prevención de la caries dental en sus hijos. ${ }^{8}$ 
Vale señalar, que la prevención de la caries dental actualmente está orientada en la educación y la promoción de las prácticas de higiene bucal, las cuales se enfocan principalmente en la etapa prenatal, es decir antes del nacimiento de los niños y niñas. ${ }^{3}$

Actualmente, existen guías regionales como las desarrolladas en Latinoamérica por la Asociación Latinoamericana de Odontopediatria - ALOP, basada en evidencia científica, con el fin de unificar pautas de salud bucal en la infancia y lograr la máxima difusión entre pediatras, médicos, enfermeras, odontólogos, odontopediatras y demás profesionales de la salud, así como madres y padres de Latinoamérica. En ellas, se proporciona de información necesaria con respecto a factores antes mencionados tales como: salud bucal durante el embarazo, salud bucal en niño en las etapas comprendidas desde el nacimiento hasta los 12 años de edad para proporcionar educación para la salud en niños y padres. ${ }^{9}$

Así entonces, empieza a desarrollarse numerosas estrategias y alternativas educacionales y motivacionales en el ámbito de salud bucodental dirigidas a las gestantes, a fin de evitar entre otros aspectos, que el S. mutans como factor etiológico indispensable en el desarrollo de la caries dental, no sea transmitido en el binomio madre-hijo, limitando por consiguiente la aparición precoz de la caries dental. ${ }^{4}$

El objetivo de la presente investigación fue identificar las prácticas preventivas de las madres frente a la ventana de infectividad bucal en el binomio madre-hijo durante la consulta de obstetricia en el hospital Universitario Ángel Larralde del estado Carabobo en el período SeptiembreDiciembre del 2017, en aras de contribuir a la odontopediatría y otras áreas de la salud, los conocimientos y herramientas requeridas para la prevención de la caries dental. Los autores quieren aportar con su estudio a la disminución de la prevalencia de la caries dental en niños, por medio del aporte del método e instrumento utilizado, que pueda ser replicado en otros centros de salud que atienden a madres gestantes o lactantes, para detectar la falta de información en esta población objeto y mejorar las conductas a seguir $\mathrm{y}$, promover la prevención temprana en salud oral en el binomio madre-hijo.

\section{Materiales y Métodos}

La investigación realizada se ubicó en el paradigma positivista, bajo el enfoque cualitativo, modalidad de campo; el diseño fue no experimental transversal, al no modificar variables y ser desarrollada en un periodo de tiempo específico. La población objeto fue conformada por treinta (30) madres que acudieron a la consulta de obstetricia en el Hospital Universitario Ángel Larralde durante los días lunes en el periodo SeptiembreDiciembre del año 2017. Se aplicó una muestra de tipo censal ya que se tomó el cien (100) de las pacientes que atendían a la consulta de ginecoobstetricia en el hospital.

En el presente estudio se utilizó como técnica de recolección de datos la encuesta (Tabla 1) y como instrumento para el levantamiento de la información un cuestionario cerrado de tipo policotómico. 
Tabla 1. Encuesta de datos.

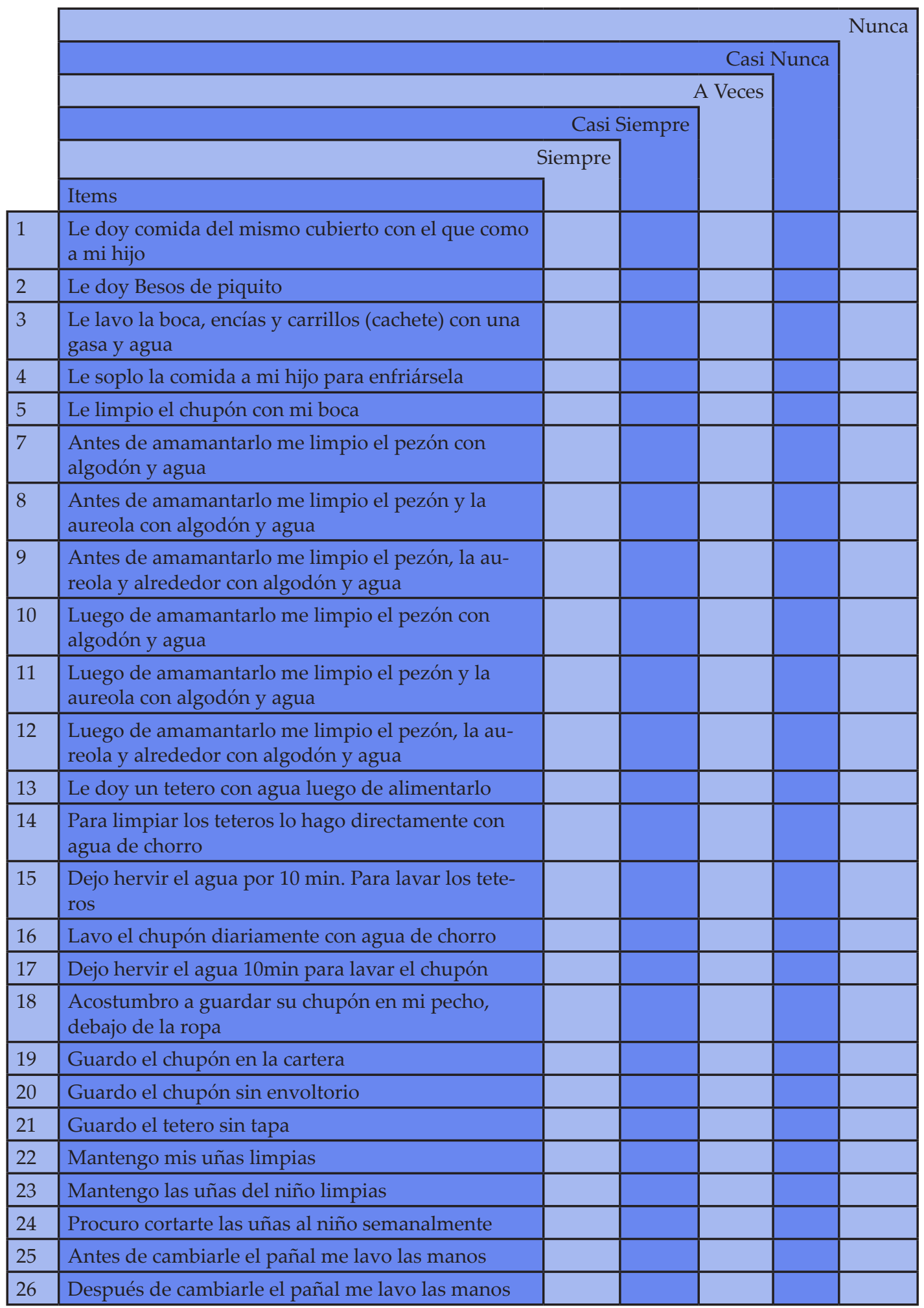


El mismo se aplicó a las treinta (30) madres queconformaronla muestraconlafinalidad de identificar los niveles de conocimientos que ellas poseen sobre los indicadores contacto directo, lactancia materna e higiene personal, y así, poder precisar las medidas preventivas requeridas en la transmisibilidad bacteriana en el binomio madre-hijo, en este caso, para determinar la exactitud con que pueden hacerse medidas significativas y adecuadas con el instrumento, siendo el mismo validado a través de juicio de expertos.

Para el diseño del instrumento, este se sometió, a la consideración de 3 expertos, un (1) experto en metodología y dos (2) especialistas en la temática abordada, quienes lo revisaron minuciosamente, con el fin de juzgar de manera independiente los ítems contenidos en el mismo, en términos de la relevancia o congruencia de los reactivos con el universo de contenido, la claridad en la redacción y la tendenciosidad o sesgo en su formulación.

La confiabilidad se determinó a través del Coeficiente de Alfa de Cronbach a partir de una prueba piloto. En psicometría, este coeficiente sirve para medir la fiabilidad de una escala de medida. El Valor mínimo aceptable es de 0,70; por debajo de ese valor la consistencia interna de la escala utilizada es baja. Por su parte, el valor máximo esperado es de 0,90; por encima de este valor se considera que existe redundancia o duplación. ${ }^{10}$

El resultado del estudio arrojó un puntaje de 0,72 ; lo cual confirma alta consistencia interna y por consiguiente la confiabilidad del mismo.

Una vez recolectada la información, se organizó y tabuló para ser presentado haciendo uso de la estadística descriptiva como herramienta de apoyo, a través de cuadros estadísticos y gráficos. El instrumento aplicado para el levantamiento de la información por medio de la distribución de frecuencia se aplicó el porcentaje para la determinación del cumplimiento y de análisis de algunas características de la población. ${ }^{11}$

\section{Resultados}

En relación a los resultados de la presente investigación para la identificación de las prácticas preventivas de las madres frente a la ventana de infectividad bucal en el binomio madre-hijo, sehizouna evaluación de las preguntas del instrumento y se ponderaron de acuerdo a sus respuestas, entiéndase como preguntas de refuerzo positivo o negativo (Tabla 2 y 3 ).

Tabla 2. Ponderación de los ítems de acción positiva para las dimensiones contacto directo, lactancia materna e higiene personal.

\begin{tabular}{|c|c|c|c|c|}
\hline \multicolumn{2}{|c|}{ Items: $3,6,7,8,9,10,11,12,14,16,21,22,23,24,25$} \\
\hline SIEMPRE & $\begin{array}{c}\text { CASI } \\
\text { SIEMPRE }\end{array}$ & $\begin{array}{c}\text { A } \\
\text { VECES }\end{array}$ & $\begin{array}{c}\text { CASI } \\
\text { NUNCA }\end{array}$ & NUNCA \\
\hline 5 & 4 & 3 & 2 & 1 \\
\hline
\end{tabular}

Tabla 3. Ponderación de los ítems de acción negativa para las dimensiones contacto directo, lactancia materna e higiene personal

\begin{tabular}{|c|c|c|c|c|}
\hline \multicolumn{4}{|l|}{ Items: 1, 2, 4, $13,15,17,18,19,20$} \\
\hline SIEMPRE & $\begin{array}{c}\text { CASI } \\
\text { SIEMPRE }\end{array}$ & $\begin{array}{c}\text { A } \\
\text { VECES }\end{array}$ & $\begin{array}{c}\text { CASI } \\
\text { NUNCA }\end{array}$ & NUNCA \\
\hline 1 & 2 & 3 & 4 & 5 \\
\hline
\end{tabular}


Seguidamente, se analizaron las respuestas, evidenciando que en las dimensiones evaluadas para el estudio de los conocimientos en relación a la transmisibilidad bacteriana por contacto directo (Grafico 1), la población encuestada presenta un nivel regular en comparación con los conocimientos de las practicas preventivas durante la lactancia materna (Grafico 2), estos resultados presentan diferencia con respecto a las medidas de higiene personal (Grafico 3), la cual resulto en un nivel bueno.

Gráfico 1. Ponderación de los items de acción negativa para las dimensiones contacto directo, lactancia materna e higiene personal.

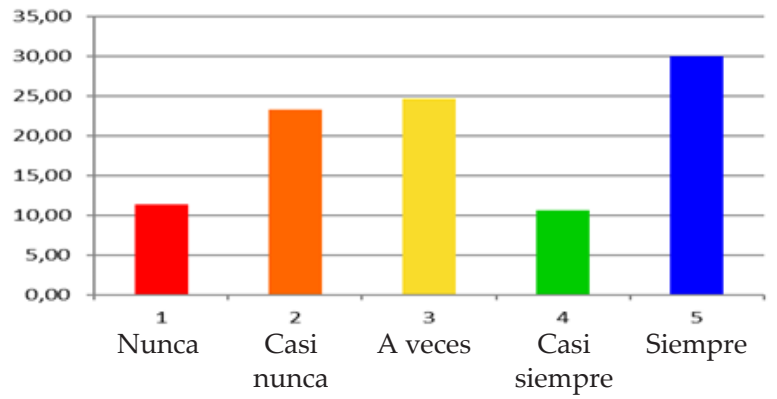

Con respecto a la dimensión por contacto directo, del total de los encuestados, se encontró que un treinta por ciento (30\%) presentó un nivel regular en cuanto a los ítems de acción negativa.

Gráfico 2. Porcentaje de la frecuencia de las respuestas en las madres según la dimensión Lactancia Materna.

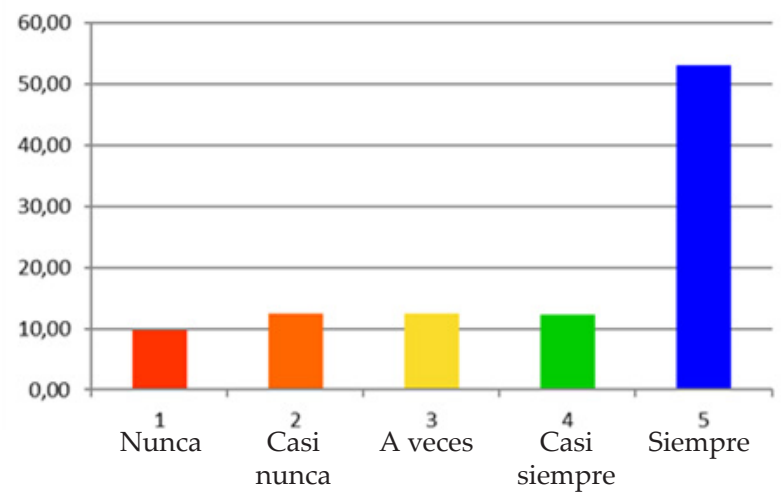

Se observó que la población encuestada presentó un nivel deficiente con respecto al conocimiento que manejan sobre las prácticas preventivas durante la lactancia materna, representado por el cincuenta $y$ tres, once por ciento $(53,11 \%)$ de las respuestas en cuanto ponderación de los ítems de acción negativa.

Gráfico 3. Frecuencia de las respuestas en las madres según la dimensión Higiene Personal.

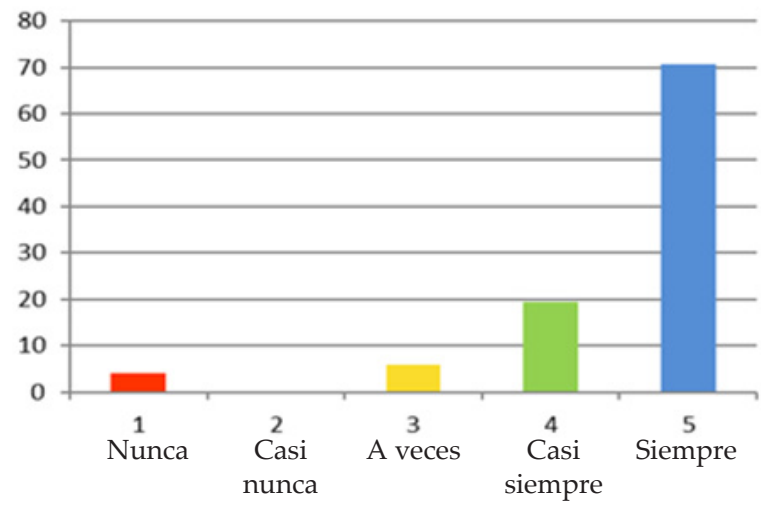

Se observó que la población encuestada presentó un nivel bueno, al hacer referencia a la dimensión higiene personal, al considerar que un setenta, sesenta y siete por ciento $(70,67 \%)$ expresó positivamente al referir sobre las medidas y conocimientos de higiene personal.

\section{Discusión}

En esta investigación se reportaron 3 niveles de conocimientos en relación a las prácticas preventivas frente a la ventana de infectividad madre-hijo, siendo un nivel regular de conocimientos para la transmisibilidad bacteriana por contacto directo, deficientes en las prácticas preventivas durante la lactancia materna y aceptable al referirse a las medidas de higiene personal. 
De acuerdo a las dimensiones estudiadas, con respecto a la dimensión por contacto directo, el total de los encuestados presentó un nivel regular de conocimientos lo cual se tradujo en información importante por parte de los encuestados en cuanto a la transmisión de la caries dental.

Sobre las prácticas preventivas durante la lactancia materna, se observó un nivel deficiente de conocimiento, siendo esto un factor influyente y predisponente durante el proceso de salud-enfermedad y en la transmisión de bacterias en la ventana de infectividad madre-hijo. En la dimensión higiene personal se observó un nivel de conocimiento aceptable que podría estar influenciado por el programa educativopreventivollevado a cabo por los residentes del postgrado de odontopediatría de la Universidad de Carabobo.

Según la literatura y los resultados obtenidos por la Organización Panamericana de la Salud, ${ }^{1}$ en la investigación se puede deducir que, aun y cuando los datos en general reflejan una percepción positiva de los conocimientos en las madres, se debe reforzar aquellos aspectos referentes al contacto directo y a la lactancia materna, debido a que se determinaron niveles deficientes en estas dimensiones; considerando que la caries dental es una enfermedad infectocontagiosa; donde participan en su transmisibilidad una serie de bacterias $^{1}$ y que por medio de la ventana de infectividad, esta población de recién nacidos están en la etapa más susceptible en adquirir bacterias, en consecuencia se incrementaría el riesgo de la aparición precoz de la caries dental. ${ }^{1}$

Al igual que Li Y, ${ }^{4}$ en este estudio se llevó a cabo un seguimiento donde se evaluó a un grupo de niños desde el momento del nacimiento hasta los 3 años de edad, en el cual mediante un estudio transversal en donde se utilizaron perfiles bacterianos, serotipados y de genotipificación, se concluyó que las madres son la principal fuente de $S$. mutans para sus bebés y se observó que la prevalencia general de $S$. mutans era del $83 \% .{ }^{10}$ Con respecto a este estudio se pudo evidenciar que las madres son la fuente principal de transmisibilidad de bacterias a los hijos no solo en los primeros días o meses de vida, sino en un periodo más amplio, siendo así de gran aporte referencial esta investigación. ${ }^{4}$

Al mismo tiempo, otros autores como Modesto et al, ${ }^{12}$ coinciden que, la principal fuente de transmisibilidad de S. mutans al niño es la madre, bien sea por contacto directo $o$ indirecto mediante fómites contaminados. ${ }^{11}$ De igual manera, Modesto, et al, en su estudio titulado "Efectos de las soluciones utilizadas en la higiene oral de los bebés sobre biofilms y microorganismos orales", menciona que la transmisión de microorganismos cariogénicos ocurre por medio de contactos directos o indirectos. ${ }^{12}$

El contacto directo vía saliva, ocurre principalmente cuando las cargas de $S$. mutans en la saliva materna son elevadas. Varios hábitos de la madre pueden promover la transmisión de bacterias: hablar cerca del niño, probar alimentos con el mismo cubierto, limpiar el chupón o pacificador con la boca o como besar al infante en la boca. El contacto indirecto ocurre por vía de objetos tales como: utensilios, cucharas, tazas, juguetes, cepillos dentales contaminados por bacterias cariogénicas o pacificadores. 
Además, el grado de transmisión va a depender de diferentes factores como: el grado de infección de los padres, cuidadores o compañeros, la frecuencia de contacto con el niño, la dieta y el estado inmune del infante. ${ }^{12}$

El estudio antes mencionado reafirma que la transmisibilidad de bacterias en el binomio madre-hijo no solo se puede presentar de manera directa debido a que otras ventanas de transmisión por el cual puede ocurrir es de manera indirecta, en relación a nuestro estudio fue por contacto indirecto gracias a utensilios o fómites contaminados por la madre. Evidenciándose así la transmisión bacteriana por vía indirecta. ${ }^{12}$

En otro estudio Chaffe $B$, et $a l,{ }^{13}$ resalta que la transmisión maternoinfantil de bacterias orales es uno de esos posibles mecanismos, dado el papel esencial, aunque no suficiente, de la infección oral en el desarrollo de la caries en niños. Las cepas bacterianas maternas pueden detectarse en niños, y la exposición a $S$. mutans salivales en madres elevados se asocia con la adquisición temprana de $S$. mutans infantil. ${ }^{13}$

Tal como ya han indicado algunos autores, es fundamental que los equipos de profesionales de la salud que están a cargo de la prevención, evaluación y diagnóstico, tanto pediatras como odontopediatras, dispongan de una adecuada formación y experiencia que les permita actuar correctamente ante la transmisión de microorganismos cariogénicos y las vías de contacto, ya que es prioritario controlar los circuitos de infectividad bucal, especialmente durante la primera infancia, cuando el sistema inmune del niño aún está inmaduro y comienza a tomar contacto con antígenos. ${ }^{12}$

Como medidas preventivas, de HsiKuei Lin, ${ }^{14}$ describen que los S. mutans son las principales bacterias causantes involucradas en la caries dental humana. En su estudio utilizaron 5 equipos de investigación que incluyeron 601 madres los resultados indicaron que la incidencia de $S$. mutans en la saliva o placa de los bebés se redujo significativamente en el grupo de madres que hicieron uso de gomas de mascar ricas en xilitol, es por esto que se ha demostrado que el consumo habitual de xilitol reduce los niveles de $S$. mutans en la saliva y la placa de las madres que tienen contacto directo con sus bebes y que no llevan a cabo prácticas preventivas con frecuencia. ${ }^{14}$

En relación a la investigación realizada se puede comparar con el estudio nombrado anteriormente, que, si existe presencia de $S$. mutans en madres y que pueden ser trasladados a la cavidad bucal de los niños si las madres no realizan con frecuencia practicas preventivas, se debe tomar en consideración y recomendar el uso de gomas de mascar con contenido de xilitol en madres para disminuir el porcentaje de $S$. mutans en la cavidad bucal de las mismas, este tipo de opciones al momento de disminuir la presencia de $S$. mutans en cavidad bucal representa un gran aporte si se realizar en conjunto con las practicas preventivas mencionadas en nuestra investigación. ${ }^{15}$

Por otra parte, Stella Tan et al, ${ }^{15}$ asevera que la transmisión de $S$. mutans de madre a hijo es ampliamente aceptada como una fuente principal de adquisición temprana de $S$. mutans en niños. Este estudio 
de transmisión también demostró que existe una gran diversidad de genotipos de $S$. mutans en la madre, pero solo se transmiten algunos genotipos maternos de S. mutans. ${ }^{15}$

Además de las fuentes maternas las cuales han demostrado ser un factor importante de transmisibilidad del S. mutans, las fuentes no maternas pueden también desempeñar un papel importante en la transmisión de $S$. mutans entre los niños pequeños, se necesitan más estudios para investigar la importancia de la formación de mutaciones de $S$. mutans contra el $S$. sobrinus en la transmisión y para identificar los factores clave en la determinación de la transmisión de Streptococcus mutans en los niños. ${ }^{16}$

Las madres encuestadas presentaron deficiencias significativas en cuanto al conocimiento de las practicas preventivas durante la lactancia materna, las madres señalaron no limpiar su pezón antes de alimentar a sus bebes y no limpiar la boca del bebe después del acto de alimentación. Así mismo, las madres demostraron poseer un conocimiento regular en relación al ítem de transmisión bacteriana por contacto directo. Se debe considerar reforzar las practicas preventivas durante la lactancia materna y de igual modo reforzar la información en cuanto a la transmisibilidad bacteriana por contacto directo en programas educativos para la prevención de la caries de la primera infancia, el cual se dirigido a gestantes y madres.

Por otro lado, en la dimensión de higiene personal, se obtuvo niveles aceptables, se debe hacer énfasis en el impacto positivo y la influencia de las actividades educacionales llevadas a cabo a través del programa de prevención y atención odontológica en la primera infancia del Postgrado de Odontopediatría de la Universidad de Carabobo en el Hospital Universitario Ángel Larralde, el cual precisamente va dirigido a la prevención de la caries dental desde la etapa prenatal de los niños y niñas por medio de las técnicas de higiene personal.

De igual modo, estos datos sitúan al Odontopediatra en una posición privilegiada para realizar la detección, diagnóstico y reporte de los niveles de educación para la salud y prevención con el que cuenta las madres en las etapas prenatal o postnatal

\section{Conclusiones}

Según los resultados obtenidos se pudo identificar las prácticas preventivas de las madres frente a la ventana de infectividad bucal en el binomio madre-hijo y por consiguiente el nivel de conocimientos que poseen las madres, en el cual se evidenció que existen 3 niveles de conocimientos al hacer referencia a las practicas preventivas frente a la ventana de infectividad madrehijo.

Se obtuvo que el nivel de conocimiento referente a la transmisibilidad bacteriana por contacto directo fue de nivel regular, las practicas preventivas durante la lactancia materna fue deficiente. El nivel de conocimiento en cuanto a las medidas de higiene personal fue aceptable. Los datos en general reflejan una percepción de nivel regular de los conocimientos en las madres. 
Cabe destacar que se debe reforzar aquellos aspectos referentes al contacto directo y a la lactancia materna, debido a que se determinaron niveles regulares y deficiente en estas dimensiones; considerando que la caries dental es una enfermedad infectocontagiosa $y$ multifactorial; donde participan en su transmisibilidad una serie de bacterias.

La identificación temprana de los elementos estudiados siempre proporcionará estados de salud bucal ideal en los niños y un estado de salud sistémica estable, asegurándonos así, la disminución de caries dental en un futuro no lejano.

\section{Recomendaciones}

Se sugiere a los postgrados de odontopediatría, reforzar las actividades educativas dirigidas a la prevención de la transmisibilidad de la flora microbiana durante los primeros días de vida, en forma de contacto directo y durante la lactancia materna, a través del pezón materno, besos, utensilios del bebe y manos de quienes lo rodean, creándose verdaderos circuitos de infectividad.

De igual modo, se recomienda difundir el presente estudio a las diferentes Áreas de las facultades de odontología de las universidades existentes, a fin de profundizar la presente investigación incorporando nuevas variables en relación a los medios más frecuentes en la transmisibilidad bacteriana en el Binomio Madre-Hijo y obtener nuevos resultados, así mismo medir el impacto en la actitud de las madres en las practicas preventivas luego de aplicar técnicas educativas.

Se sugiere la difusión y uso de las guías educativas tanto para personal general, como en pediatría médica y odontología de la región, donde se recomiendan aspectos básicos de prevención relativos a este tema.

\section{Referencias bibliográficas}

1. OPS. La salud en las Américas. OPS. Publicación Científica y Técnica. 2002; vol. I y II No 587

2. Palomer L. Caries Dental en el Niño. Rev Chil Pediatr. 2006; 77 (1): 56-60.

3. Olga S, Noel MS, K. Childers K. Anticipatory Guidance in Infant Oral Health AAFP, University of Alabama. 2000; 61(1):115-120.

4. Caufield P, Li Y. The fidelity of initial acquisition of mutans streptococci by infants from their mothers. J Dent Res. 1995; 74(2): 681-85.

5. Francisco, R. Daniela, R. Clarice, S. Rebecca, L. Brendan, J. James, J. Community-Based Dental Education. J Dent Educ. 2014; 78(12):1593-603.

6. Rotemberg W, Smaisik F. Inmunidad bucal en la primera infancia. Odontoestomatología. 2010; 12 (14): 4-14.

7. Dankhe G, Fernández C. La Comunicación Humana: Ciencia Social. 2da ed. México: Ed. McGraw-Hill; 1989.

8. Castaño H. Circuito de Infectividad Bucal entre Madre- Hijo. Rev. Asociación Odontológica Argentina. 2010; 91 (4): 305-310. 
9. Asociación Latinoamericana de Odontopediatría, ALOP. Revista de Odontopediatría: Folletos Educativos. [citado 2 sept 2018]. Disponible en: https://www.revistaodontopediatria.org/publicaciones/\#Manual-deReferencia-para-Procedimientos-en-Odontopediatria.

10. Oviedo H. Aproximación al Uso del Coeficiente Alfa de Cronbach. Revista Colombiana de Psiquiatría. 2005; 34 (4): 572-580.

11. Cerda C. Educación a Distancia: Principios y Tendencias. Rev. Latinoamericana de Estudios Educativos. 2007; 27: 11-30

12. Modesto A, Lima KC, Uzeda M. Effects of solutions used in infant's oral hygiene on biofilms and oral microorganisms. ASDC J Dent Child. 2000; 67(5): 338-44.

13. Chaffee SA. Gansky JA. Weintraub. Maternal Oral Bacterial Levels Predict Early Childhood Caries Development. J Dent Res. 2014; 93(3): 238-244.

14. His, L Chia ,F. Mao, H. Effect of maternal use of chewing gums containing xylitol on transmission of mutans streptococci in children: a meta-analysis of randomized controlled trials. International J Pediatrics Dentistry. 2015; 26(1): 35-44.

15. Ling Z, Tan S, Den Besten P, D.B J, Hoover Ch. Factors Related to Maternal Transmission of Mutans Streptococci in High-Risk Children-Pilot Study. Pediatr Dent. 2012; 34: e86-e91.

16. Organización Mundial de la Salud (OMS). Programa Mundial de Salud Bucodental, Abril 2012, nota informativa $\mathrm{N}^{\circ} 318$.

Recibido: 07/08/2018

Aceptado: 21/02/2019

Correspondencia: Patricia Catarí, email: patriciacatari@hotmail.com 